Vol 13, Issue 5, 2020

\title{
DEVELOPMENT AND VALIDATION OF A GAS CHROMATOGRAPHY HEADSPACE METHOD FOR THE SIMULTANEOUS QUANTIFICATION OF SIX ORGANIC VOLATILE IMPURITIES IN SUMATRIPTAN SUCCINATEAPI AND ITS PHARMACEUTICAL DOSAGE FORMS
}

\author{
KRISHNA KISHORE J, PRASADA RAO K* \\ Department of Chemistry, ANU Research Centre, Bapatla Engineering College, Guntur, Andhra Pradesh, India. \\ Email: krishna4kishorephd@gmail.com
}

Received: 24 February 2020, Revised and Accepted: 22 April 2020

\begin{abstract}
Objective: The main aim of this study, to develop a validated analytical method for simultaneous quantification of six organic volatile impurities (OVI) in sumatriptan succinate active pharmaceutical ingredients (API) and its pharmaceutical dosage forms by headspace (HS)-gas chromatography (GC).

Methods: The method development and its validation were performed on a Shimadzu GC-2010 GC system equipped with a flame ionization detector and Teledynetekmar HT3 ${ }^{\mathrm{TM}}$ HS analyzer. The method involved a thermal gradient elution of six OVI present in sumatriptan succinate API. DB-624, 30 $\mathrm{m} \times 0.53 \mathrm{~mm}, 3.0 \mu$ column is used as a stationary phase and nitrogen gas is used as a carrier gas. The flow rate was $2.8 \mathrm{~mL} / \mathrm{min}$ and the flame ionization detector temperature is $260^{\circ} \mathrm{C}$.
\end{abstract}

Results: The correlation coefficient $\left(\mathrm{r}^{2}\right)$ was not $<0.99$ at the limit of quantification (LOQ) to $150 \%$. The limit of detection obtained for methanol, acetone, isopropyl alcohol, dichloromethane, benzene, and toluene was found 18.4, 8.8, 5.5, 4.3, 0.04, and 4.2 ppm. The LOQ obtained was 55.8, 26.8, $16.6,13.0,0.1$, and $12.6 \mathrm{ppm}$. Accuracy results were obtained from 85 to $115 \%$ for six OVI's. Furthermore, verified precision, ruggedness, robustness, solution stability, and pharmaceutical analysis. All the results are found within the acceptable limits.

Conclusion: The method presents a simple and reliable solution for the routine quantitative analysis of organic volatile impurities present in sumatriptan succinate API.

Keywords: Methanol, Acetone, Isopropyl alcohol, Dichloromethane, Benzene, Toluene, Sumatriptan Succinate active pharmaceutical ingredients, Method development and Validation.

(C) 2020 The Authors. Published by Innovare Academic Sciences Pvt Ltd. This is an open access article under the CC BY license (http://creativecommons. org/licenses/by/4. 0/) DOI: http://dx.doi.org/10.22159/ajpcr.2020.v13i5.37260

\section{INTRODUCTION}

Sumatriptan succinate (Fig. 1) is chemically 3-[2-(dimethylamino) ethyl]-N-methyl- indole-5-methanesulfonamide succinate [1]. Chemical formula is $\mathrm{C}_{18} \mathrm{H}_{27} \mathrm{~N}_{3} \mathrm{O}_{6} \mathrm{~S}$ and molecular weight is $413.5 \mathrm{~g} / \mathrm{mol}$.

Organic volatile chemicals used in synthesis and process chemistry of drug substances. There is an existing International Conference on Harmonization (ICH) guideline for residual solvents in pharmaceuticals (ICH 1997).

\section{LITERATURE REVIEW}

A literature survey regarding the quantitative analysis of sumatriptan succinate revealed that attempts were made to the estimation of sumatriptan succinate in bulk and pharmaceutical dosage forms by high-performance liquid chromatography (HPLC) [1,2] and simultaneous estimation of sumatriptan succinate, metoclopramide hydrochloride, and paracetamol by reverse-phase HPLC [3].

In this study, methanol, acetone, isopropyl alcohol (IPA), dichloromethane, benzene, and toluene were taken as a volatile organic impurity (Fig. 2). The specifications for the six organic volatile impurities were taken very low level compared with ICH specifications. The results obtained were validated according to the ICH guidelines.

\section{METHODS}

Chemicals and reagents

Methanol (HPLC grade), acetone (HPLC grade), IPA (HPLC grade), dichloromethane (gas chromatography [GC] grade), benzene (HPLC grade), toluene (HPLC grade), and dimethyl sulfoxide (DMSO) (GC grade) were provided by Sigma-Aldrich. Sumatriptan succinate active pharmaceutical ingredients (API) are taken from a local research laboratory. DMSO is used as a diluent and blank.

\section{Apparatus and chromatographic conditions}

Chromatography was performed on a Shimadzu chromatographic system equipped with a Shimadzu GC-2010 system with a flame ionization detector (FID), samples were injected through a Teledyne Tekmar HT $^{\mathrm{TM}}{ }^{\mathrm{M}}$ Headspace (HS). Data acquisition and integration were performed using GC solution software. The instrument parameters described below were set up to determine the organic volatile impurities.

\section{GC conditions}

The column was DB-624 $3.0 \mu \mathrm{m}$ film thickness, $30 \mathrm{~m}$, and $0.53 \mathrm{~mm}$. The column flow is $2.8 \mathrm{~mL} / \mathrm{min}$ injector temperature: $220^{\circ} \mathrm{C}$. The detector temperature is $260^{\circ} \mathrm{C}$. The oven program is, initial temperature is $40^{\circ} \mathrm{C}$ hold for $5 \mathrm{~min}$ and increase the ramp rate $20^{\circ} \mathrm{C} / \mathrm{min}$ up to $200^{\circ} \mathrm{C}$ and hold for $12 \mathrm{~min}$. The split ratio is $20: 1$ and the carrier gas is $\mathrm{N}_{2}$.

\section{HS conditions}

Vial temperature is $90^{\circ} \mathrm{C}$, oven temperature is $100^{\circ} \mathrm{C}$, transfer line temperature is $110^{\circ} \mathrm{C}$, vial equilibration time is $25 \mathrm{~min}$, inject time is $1.0 \mathrm{~min}$, and GC cycle time is $35 \mathrm{~min}$.

\section{Preparation of solutions}

Specifications for organic volatile impurities

Methanol is $2000 \mathrm{ppm}$, acetone is $1000 \mathrm{ppm}$, IPA is $500 \mathrm{ppm}$, dichloromethane is $500 \mathrm{ppm}$, benzene is $2.0 \mathrm{ppm}$, and toluene is $500 \mathrm{ppm}$. 


\section{Benzene standard stock solution}

Weigh and transferred about $250 \mathrm{mg}$ of benzene into a $50 \mathrm{~mL}$ of the volumetric flask containing $30 \mathrm{~mL}$ of diluent and diluted to volume with diluent. Further taken $1.0 \mathrm{~mL}$ of above solution into $100 \mathrm{~mL}$ of volumetric flask and diluted to volume with diluent.

\section{Standard solution preparation}

Weigh and transferred about each $500 \mathrm{mg}$ of methanol, $250 \mathrm{mg}$ of acetone, $125 \mathrm{mg}$ of IPA, $125 \mathrm{mg}$ of dichloromethane, and $125 \mathrm{mg}$ of toluene into a $100 \mathrm{~mL}$ of the volumetric flask containing $70 \mathrm{~mL}$ of diluent and diluted to volume with diluent. Further taken $5.0 \mathrm{~mL}$ of the above solution and $0.5 \mathrm{~mL}$ of benzene stock solution into $50 \mathrm{~mL}$ of volumetric flask and diluted to volume with diluent.

The standard HS vials were prepared with $2 \mathrm{~mL}$ of the standard solution and seal the vial with aluminum closure (the standard solution concentration was prepared concerning sample concentration).

Preparation of sumatriptan succinate API sample solution $(250 \mathrm{mg} / \mathrm{mL})$ Accurately weighed about $500 \mathrm{mg}$ of sumatriptan succinate API into an HS vial and add $2.0 \mathrm{~mL}$ of DMSO was accurately pipetted into the sample vial. The vial was sealed with aluminum closure.

\section{Preparation of sumatriptan succinate tablet solution}

Twenty tablets were weighed and powdered. An amount of powder equivalent to $500 \mathrm{mg}$ sumatriptan succinate was accurately weighed and transferred to an $\mathrm{HS}$ vial, add $2 \mathrm{~mL}$ of diluent and seal with an aluminum septum and crimp the cap.

\section{Calculation}

The organic volatile impurity content was calculated from,

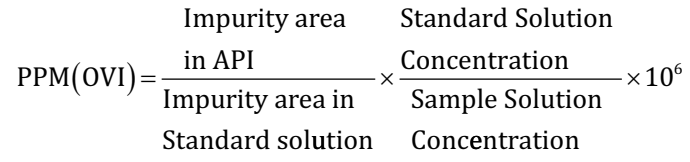

\section{RESULTS AND DISCUSSION}

\section{Method development}

The GC-HS method has been developed as stepwise strategies.

\section{Column selection}

The primary goal of column selection was to resolve a total of six organic volatile impurities which were used during the synthesis and manufacturing of sumatriptan succinate API. Several columns were initially investigated to finalize a single column for the separation and quantitation of organic volatile impurities. Wall-coated capillary columns of various brands with a variety of phases and dimensions have been investigated. The $1^{\text {st }}$ column is DB- 1 (30 m length, $0.32 \mathrm{~mm}$ i.d, $1.0 \mu$ film thickness). The $2^{\text {nd }}$ column is VF- $624 \mathrm{~ms}$ ( $60 \mathrm{~m}$ length, 0.32 $\mathrm{mm}$ i.d, $1.0 \mu$ film thickness). Moreover, the $3^{\text {rd }}$ column is DB-624 (30 m length, $0.32 \mathrm{~mm}$ i.d, $3.0 \mu$ film thickness). In the above the $1^{\text {st }}$ and $2^{\text {nd }}$ columns, the response was found to be comparatively lower and peak shapes were found to be unsatisfactory, and the resolution is not good. However, the $3^{\text {rd }}$ column has given good resolution, tailing, and good peak shapes. Therefore, DB-624 (30 m length, $0.53 \mathrm{~mm}$ i.d, $3.0 \mu$ film thickness) proved to be the best column that could fulfill all the needs of the method, those are higher sensitivity, shorter runtime, and higher resolution between the critical pairs.

\section{HS method optimization}

The HS method was optimized in such a way that the maximum amount of the organic volatile impurities presents in the sumatriptan succinate API gets evaporated for the detection. For this, the standard and sample vials were heated at $70^{\circ} \mathrm{C}-100^{\circ} \mathrm{C}$ for $15-30 \mathrm{~min}$ with constant shaking. A combination of sample vial heating at $90^{\circ} \mathrm{C}$ with $25 \mathrm{~min}$ shaking was found to be suitable for getting a good response.

\section{Method validation}

The developed GC-HS method has been validated as per ICH guideline [4].

\section{Specificity}

The relative retention time of the six OVI's indicated that they were well separated from each other (Table 1). The typical chromatograms of six organic volatile impurities and sumatriptan succinate API is shown in Fig. 3.

\section{System suitability}

System suitability was evaluated by injecting six replicates of standard solution into the chromatographic system as per the test method. The $\%$ relative standard deviation (RSD) was calculated for the area of six OVI's. The \% RSD of each impurity is not more than (NMT) $15.0 \%$. Results and typical chromatograms are shown in Table 2 and Fig. 4.

\section{Method precision}

Method precision was evaluated by preparing the six different preparations of standard solution into the chromatographic system as per the test method. \% RSD was calculated for the area of six preparations. The \% RSD of each organic volatile impurity is NMT $15.0 \%$. Results and typical chromatograms are shown in Table 3 and Fig. 5.

Linearity at low level for limit of detection (LOD) and limit of quantification (LOQ)

The linearity of the method was determined over the concentration range of $5 \%, 10 \%, 15 \%, 20 \%$, and $25 \%$ concerning the sumatriptan succinate API. The LOD and LOQ were calculated from these linearity data and shown in Table 4.

\section{LOD and LOQ}

The LOD and LOQ for the proposed method were determined using calibration standards and calculated using $3.3 \mathrm{\sigma} / \mathrm{s}$ and $10 \mathrm{\sigma} / \mathrm{s}$ formulae, respectively. The data and typical chromatograms are as shown in Table 5 and Fig. 6.

\section{Linearity with LOQ}

The linearity of the method was determined over the concentration range of LOQ $\%, 50 \%, 75 \% 100 \%, 125 \%$, and $150 \%$. The correlation coefficient $\left(\mathrm{r}^{2}\right)$ of each impurity is not $<0.99$. The obtained results and typical chromatograms for linearity as shown in Table 6 and Fig. 7.

\section{LOQ-precision}

The \% RSD of the area obtained from six standard injections at LOQ level was calculated. The \% RSD is abstained NMT 15.0\%. The obtained results and typical chromatograms for LOQ precision as shown in Table 7 and Fig. 8.

\section{Accuracy}

The accuracy was evaluated by the \% recoveries of the six organic volatile impurities spiked with the sumatriptan succinate sample API. The acceptance criterion for accuracy was that should be in the range of 85-115\%. The results are indicated in Table 8.

\section{LOQ accuracy}

The $\%$ recovery of each organic volatile impurity at the LOQ level should be within $100 \pm 15 \%$. The results are shown in Table 9 .<smiles>CNS(=O)(=O)Cc1ccc2[nH]cc(CCN(C)C)c2c1</smiles>

Fig. 1: Chemical Structure of sumatriptan succinate 
$\mathrm{CH}_{3}-\mathrm{OH}$

Methanol

Chemical Formula: $\mathrm{CH}_{3} \mathrm{OH}$

$$
\mathrm{Cl} \mathrm{Cl}
$$

Dichloromethane Chemical Formula: $\mathrm{CH}_{2} \mathrm{Cl}_{2}$<smiles>CC(C)=O</smiles>

Acetone

Chemical Formula: $\mathrm{C}_{2} \mathrm{H}_{6} \mathrm{O}$

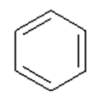

Benzene

Chemical Formula: $\mathrm{C}_{6} \mathrm{H}_{6}$

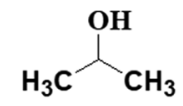

Isopropyl alcohol

Chemical Formula: $\mathrm{C}_{3} \mathrm{H}_{8} \mathrm{O}$

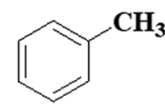

Toluene

Chemical Formula: $\mathrm{C}_{7} \mathrm{H}_{8}$

Fig. 2: Chemical structures of six organic volatile impurities
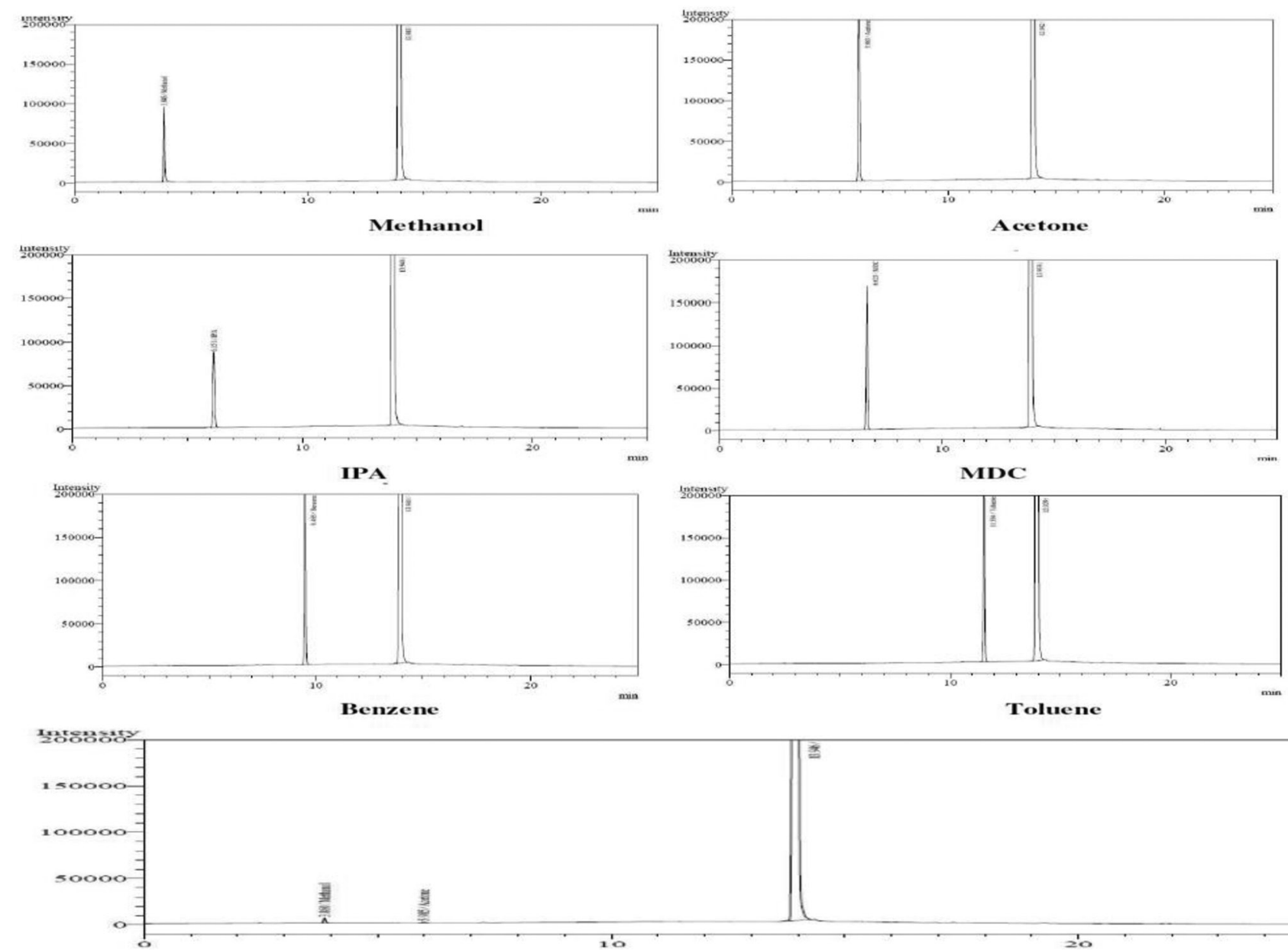

Toluene

Fig. 3: Typical chromatograms of six organic volatile impurities standard and sumatriptan succinate

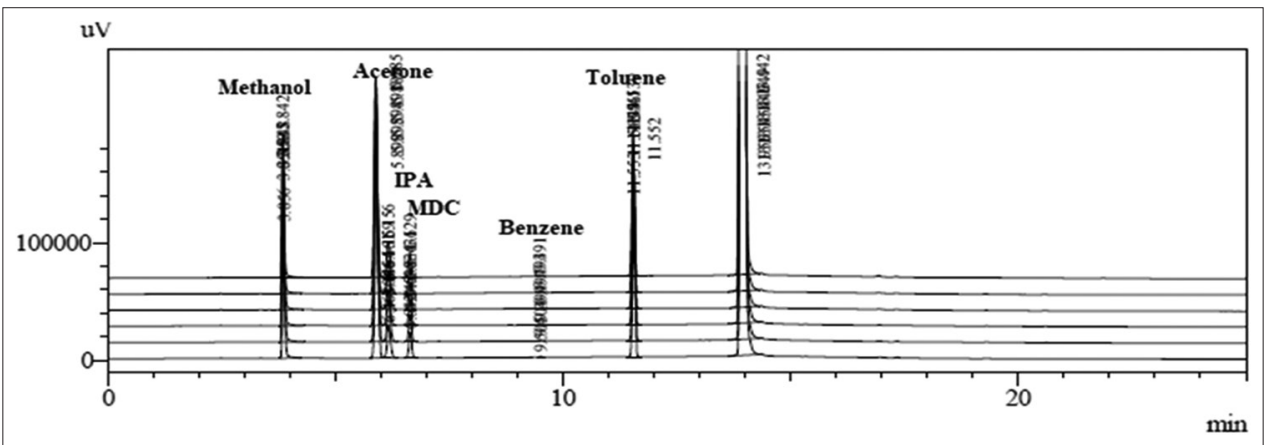

Fig. 4: Typical chromatogram for system suitability 


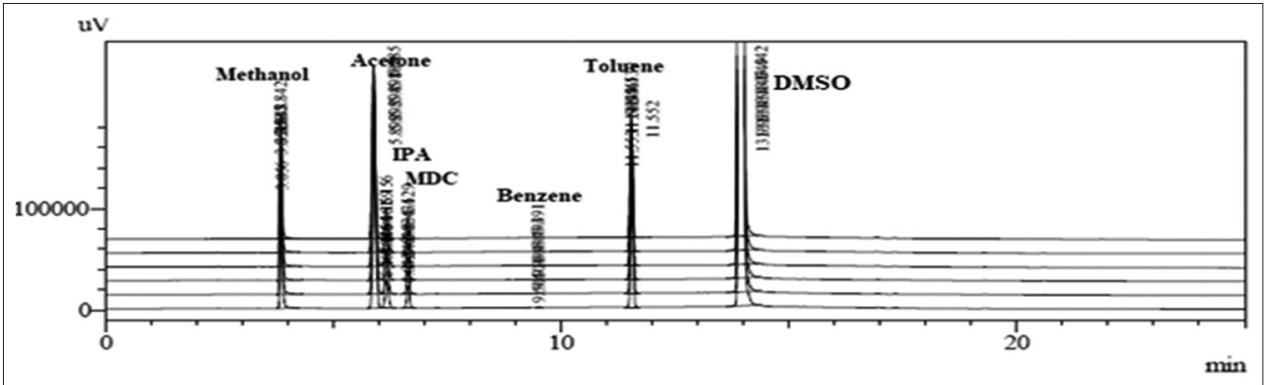

Fig. 5: Typical chromatogram for method precision

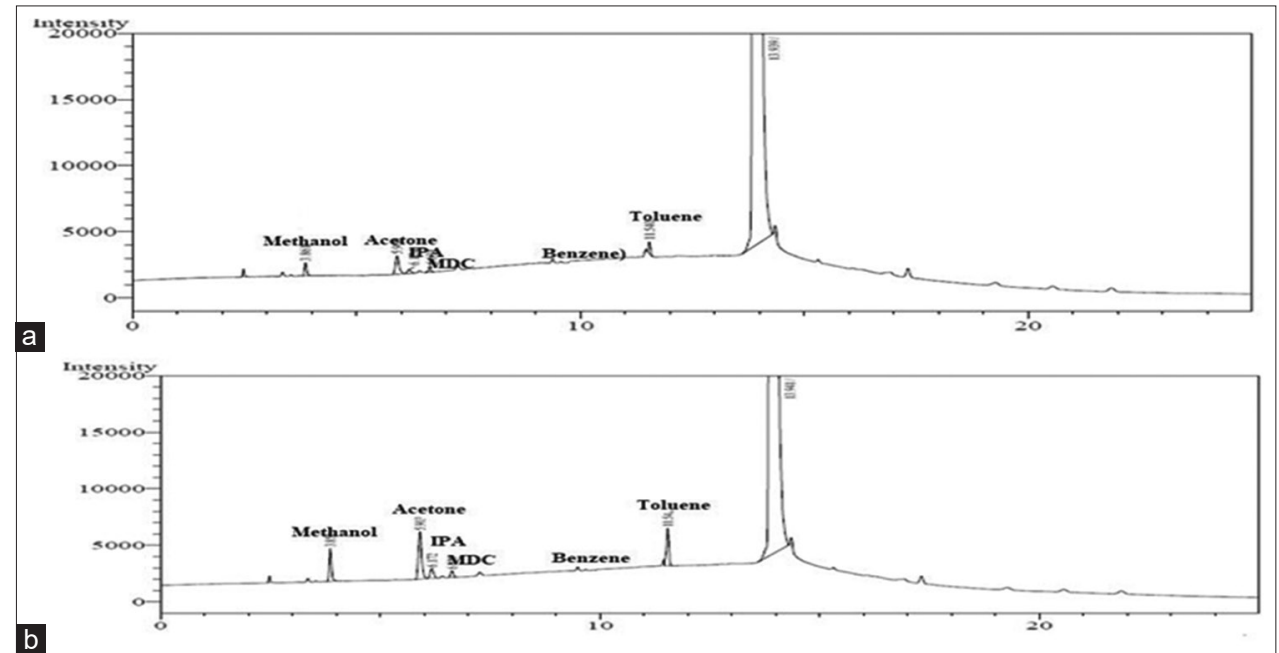

Fig. 6: (a) Limit of detection and (b) limit of quantitation chromatogram of six organic volatile impurities

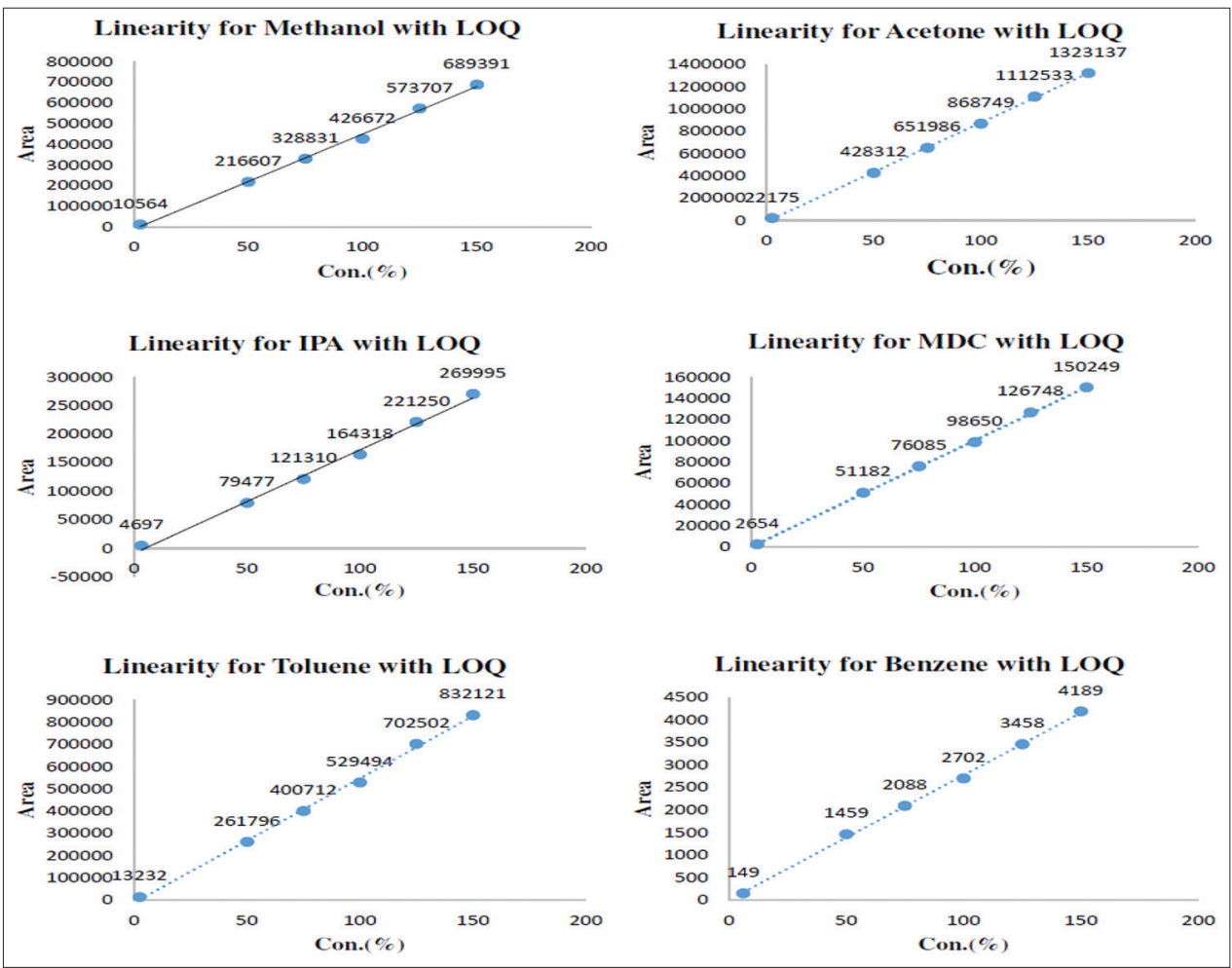

Fig. 7: Linearity with a limit of quantitation graphs of six organic volatile impurities 
Table 1: Specificity data for six organic volatile impurities

\begin{tabular}{|c|c|c|c|c|c|}
\hline S. no. & Name of OVI's & RT (min) & Theoretical plates & Tailing factor & USP resolution \\
\hline 1. & Methanol & 3.84 & 31,500 & 1.24 & --- \\
\hline 2. & Acetone & 5.88 & 31,592 & 1.25 & 18.81 \\
\hline 3. & IPA & 6.15 & 31,870 & 1.24 & 2.00 \\
\hline 4. & MDC & 6.62 & 31,378 & 1.25 & 3.63 \\
\hline 5. & Benzene & 9.49 & 31,895 & 1.23 & 24.58 \\
\hline 6. & Toluene & 11.53 & 31,437 & 1.25 & 19.28 \\
\hline
\end{tabular}

OVI's: Organic volatile impurities, IPA: Isopropyl alcohol, MDC: Methylene dichloride, USP: United States pharmacopeia

Table 2: System suitability data for six organic volatile impurities

\begin{tabular}{|c|c|c|c|c|c|c|}
\hline No. of injections & Area of methanol & Area of acetone & Area of IPA & Area of MDC & Area of benzene & Area of toluene \\
\hline 1. & 419,110 & 836,915 & 157,745 & 93,538 & 2588 & 498,177 \\
\hline 2. & 387,746 & 855,404 & 145,905 & 95,052 & 2625 & 501,092 \\
\hline 3. & 437,461 & 857,082 & 169,561 & 961,97 & 2703 & 527,798 \\
\hline 4. & 414,158 & 866,166 & 158,704 & 96,748 & 2702 & 519,538 \\
\hline 5. & 494,852 & 901,815 & 191,123 & 103,363 & 2900 & 584,455 \\
\hline 6 & 386,431 & 866,780 & 144,871 & 95,838 & 2654 & 506,330 \\
\hline AVG. & 423,293 & 864,027 & 161,318 & 96,789 & 2695 & 522,898 \\
\hline RSD (\%) & 9.48 & 2.48 & 10.68 & 3.52 & 4.07 & 6.16 \\
\hline
\end{tabular}

IPA: Isopropyl alcohol, MDC: Methylene dichloride, RSD: Relative standard deviation

Table 3: Method precision data for six organic volatile impurities

\begin{tabular}{|c|c|c|c|c|c|c|}
\hline No. of injections & Area of methanol & Area of acetone & Area of IPA & Area of MDC & Area of benzene & Area of toluene \\
\hline 1. & 549,752 & 865,575 & 152,638 & 97,377 & 2648 & 513,474 \\
\hline 2. & 583,141 & 883,989 & 162,296 & 100,231 & 2720 & 541,205 \\
\hline 3. & 628,288 & 899,525 & 177,205 & 103,111 & 2962 & 566,302 \\
\hline 4. & 594,609 & 884,003 & 166,781 & 99,914 & 2827 & 538,721 \\
\hline 5. & 742,800 & 937,860 & 209,916 & 109,668 & 3050 & 625,924 \\
\hline 6 & 650,688 & 893,877 & 184,865 & 102,314 & 2847 & 561,709 \\
\hline ACVG. & 624,880 & 894,138 & 175,617 & 102,103 & 2842 & 557,889 \\
\hline RSD (\%) & 10.83 & 2.72 & 11.52 & 4.13 & 5.23 & 6.86 \\
\hline
\end{tabular}

IPA: Isopropyl alcohol, MDC: Methylene dichloride, RSD: Relative standard deviation

Table 4: Low-level linearity data for LOD and LOQ

\begin{tabular}{|c|c|c|c|c|c|c|}
\hline Con. (\%) & $\begin{array}{l}\text { Methanol average } \\
\text { area }(n=2)\end{array}$ & $\begin{array}{l}\text { Acetone average area } \\
(n=2)\end{array}$ & $\begin{array}{l}\text { IPA average } \\
\text { area }(n=2)\end{array}$ & $\begin{array}{l}\text { MDC average area } \\
(n=2)\end{array}$ & $\begin{array}{l}\text { Benzene average area } \\
(n=2)\end{array}$ & $\begin{array}{l}\text { Toluene average area } \\
(n=2)\end{array}$ \\
\hline 5 & 18,784 & 40,776 & 7099 & 4796 & 115 & 26,659 \\
\hline 10 & 40,563 & 85,649 & 15,676 & 10,151 & 238 & 53,845 \\
\hline 15 & 59,479 & 121,965 & 23,446 & 14,456 & 358 & 76,261 \\
\hline 20 & 78,221 & 165,878 & 30,434 & 19,422 & 481 & 100,954 \\
\hline 25 & 97,106 & 208,443 & 38,007 & 24,346 & 646 & 126,971 \\
\hline$r^{2}$ & 1.000 & 1.000 & 0.999 & 1.000 & 0.998 & 1.000 \\
\hline STEYX & 1084 & 2223 & 508 & 250 & 16 & 1242 \\
\hline SLOPE & 3886 & 8311 & 1531 & 967 & 26 & 4955 \\
\hline LOQ (\%) & 2.79 & 2.68 & 3.32 & 2.59 & 6.09 & 2.51 \\
\hline LOD (\%) & 0.92 & 0.88 & 1.10 & 0.85 & 2.01 & 0.83 \\
\hline
\end{tabular}

LOD: Limit of detection, LOQ: Limit of quantitation, IPA: Isopropyl alcohol, MDC: Methylene dichloride

Table 5: LOD and LOQ data for six organic volatile impurities

\begin{tabular}{lllll}
\hline OVI's & $\begin{array}{l}\text { LOD con. } \\
\text { (ppm) }\end{array}$ & $\begin{array}{l}\text { LOQ con. } \\
\text { (ppm) }\end{array}$ & $\begin{array}{l}\text { LOD } \\
\text { area }\end{array}$ & $\begin{array}{l}\text { LOQ } \\
\text { area }\end{array}$ \\
\hline Methanol & 18.4 & 55.8 & 3607 & 10,564 \\
Acetone & 8.8 & 26.8 & 7803 & 22,175 \\
IPA & 5.5 & 16.6 & 1628 & 4697 \\
MDC & 4.3 & 13.0 & 921 & 2654 \\
Benzene & 0.04 & 0.1 & 52 & 149 \\
Toluene & 4.2 & 12.6 & 2758 & 13,232 \\
\hline
\end{tabular}

LOD: Limit of detection, LOQ: Limit of quantitation, IPA: Isopropyl alcohol, MDC: Methylene dichloride
Ruggedness

The ruggedness of the method was evaluated by performing the sample analysis in six replicates by different analysts on different days and the results are summarized as shown in Table 10 . The \% RSD values of six organic volatile impurities are NMT $15.0 \%$.

\section{Robustness}

This study was performed by making small variations in the method parameters. The variation in the column flow $2.5 \mathrm{~mL} / \mathrm{min}$ and $3.1 \mathrm{~mL} / \mathrm{min}$, vial condition temperature $75^{\circ} \mathrm{C}$ and $85^{\circ} \mathrm{C}$ was done. The obtained \% RSD is not more than $15 \%$ for every changed method parameter. The results are shown in Table 11. 




Fig. 8: Limit of quantitation-precision overlay chromatogram for six organic volatile impurities

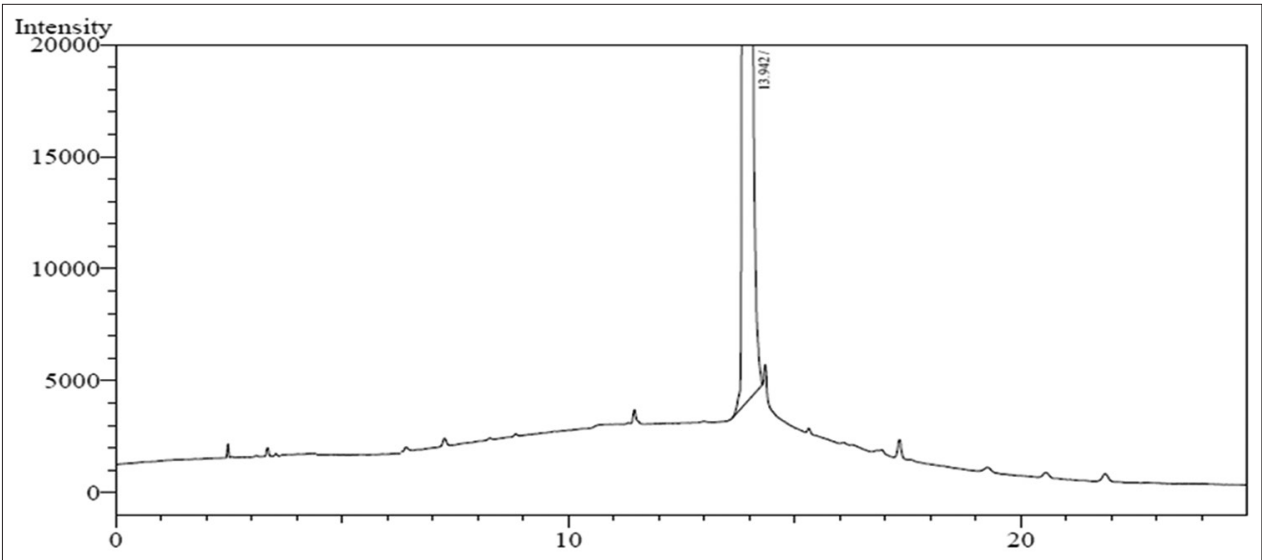

Fig. 9: Typical chromatogram for sumatriptan succinate tablet

Table 6: Linearity data with LOQ

\begin{tabular}{lllllll}
\hline Con. (\%) & $\begin{array}{l}\text { Methanol average } \\
\text { area }(\mathbf{n = 2})\end{array}$ & $\begin{array}{l}\text { Acetone average } \\
\text { area }(\mathbf{n = 2})\end{array}$ & $\begin{array}{l}\text { IPA average area } \\
\mathbf{( n = 2 )}\end{array}$ & $\begin{array}{l}\text { MDC average area } \\
\mathbf{( n = 2 )}\end{array}$ & $\begin{array}{l}\text { Benzene average } \\
\text { area }(\mathbf{n = 2})\end{array}$ & $\begin{array}{l}\text { Toluene average } \\
\text { area }(\mathbf{n}=\mathbf{2})\end{array}$ \\
\hline${ }^{*} \mathrm{LOQ}$ & 10,564 & 22,175 & 4697 & 2654 & 149 & 13,232 \\
50 & 216,607 & 428,312 & 79,477 & 51,182 & 1459 & 261,796 \\
75 & 328,831 & 651,986 & 121,310 & 76,085 & 2088 & 400,712 \\
100 & 426,672 & 868,749 & 164,318 & 98,650 & 2702 & 702,594 \\
125 & 573,707 & $1,112,533$ & 221,250 & 126,748 & 832,121 \\
150 & 689,391 & $1,323,137$ & 269,995 & 150,249 & 3458 & 0.999 \\
$\mathrm{r}^{2}$ & 0.999 & 1.000 & 0.998 & 1.000 & 4189 & 0.999 \\
\hline
\end{tabular}

*LOQ (\%): 2.79\% for methanol, 2.68\% for acetone, 3.32\% for IPA, 2.59\% for MDC, 6.09\% for benzene and 2.51\% for toluene. LOD: Limit of detection, LOQ: Limit of quantitation, IPA: Isopropyl alcohol, MDC: Methylene dichloride

Table 7: LOQ-precision data

\begin{tabular}{|c|c|c|c|c|c|c|}
\hline No. of injections & Area of methanol & Area of acetone & Area of IPA & Area of MDC & Area of benzene & Area of toluene \\
\hline Run-1 & 10441 & 22071 & 4752 & 2609 & 152 & 12865 \\
\hline Run-2 & 9898 & 22061 & 4519 & 2581 & 155 & 12990 \\
\hline Run-3 & 10114 & 21815 & 4562 & 2590 & 148 & 12837 \\
\hline Run-4 & 10134 & 21907 & 4600 & 2542 & 144 & 13027 \\
\hline Run-5 & 11140 & 21381 & 5295 & 2519 & 160 & 13208 \\
\hline Run-6 & 10564 & 22175 & 4697 & 2654 & 158 & 13232 \\
\hline ACVG & 10382 & 21902 & 4738 & 2583 & 153 & 13027 \\
\hline RSD (\%) & 4.26 & 1.30 & 6.05 & 1.86 & 3.98 & 1.28 \\
\hline
\end{tabular}

IPA: Isopropyl alcohol, MDC: Methylene dichloride, LOQ: Limit of quantitation 
Table 7: LOQ-precision data

\begin{tabular}{|c|c|c|c|c|c|c|}
\hline No. of injections & Area of methanol & Area of acetone & Area of IPA & Area of MDC & Area of benzene & Area of toluene \\
\hline Run-1 & 10441 & 22071 & 4752 & 2609 & 152 & 12865 \\
\hline Run-2 & 9898 & 22061 & 4519 & 2581 & 155 & 12990 \\
\hline Run-3 & 10114 & 21815 & 4562 & 2590 & 148 & 12837 \\
\hline Run-4 & 10134 & 21907 & 4600 & 2542 & 144 & 13027 \\
\hline Run-5 & 11140 & 21381 & 5295 & 2519 & 160 & 13208 \\
\hline Run-6 & 10564 & 22175 & 4697 & 2654 & 158 & 13232 \\
\hline ACVG & 10382 & 21902 & 4738 & 2583 & 153 & 13027 \\
\hline RSD (\%) & 4.26 & 1.30 & 6.05 & 1.86 & 3.98 & 1.28 \\
\hline
\end{tabular}

IPA: Isopropyl alcohol, MDC: Methylene dichloride, LOQ: Limit of quantitation

Table 8: Recovery data for six organic volatile impurities

\begin{tabular}{|c|c|c|c|c|c|c|c|}
\hline \multirow{2}{*}{$\begin{array}{l}\text { OVI's } \\
\text { Methanol }\end{array}$} & \multirow{2}{*}{$\begin{array}{l}\text { Average sample } \\
\text { area }(\mathbf{n}=3) \\
20,720\end{array}$} & \multirow{2}{*}{$\begin{array}{l}\text { Average STD } \\
\text { area }(\mathbf{n}=\mathbf{3}) \\
423,293\end{array}$} & \multirow{2}{*}{$\begin{array}{l}\text { Average } 50 \% \\
\text { area }(\mathbf{n}=3)\end{array}$} & \multirow{2}{*}{$\begin{array}{l}\text { Average } 100 \% \\
\text { area }(\mathbf{n}=3) \\
448,403\end{array}$} & \multirow{2}{*}{$\begin{array}{l}\text { Average } 150 \% \\
\text { area }(\mathbf{n}=3) \\
677,886\end{array}$} & \multicolumn{2}{|c|}{$\begin{array}{l}\% \text { recovery at } 50,100 \text {, } \\
\text { and } 150 \%\end{array}$} \\
\hline & & & & & & 50 & 93.63 \\
\hline & & & & & & 150 & 103.50 \\
\hline \multirow[t]{3}{*}{ Acetone } & 6248 & 864,027 & 429,669 & 879,057 & $1,322,004$ & 50 & 98.01 \\
\hline & & & & & & 100 & 101.02 \\
\hline & & & & & & 150 & 101.52 \\
\hline \multirow{2}{*}{ IPA } & & & & & & 100 & 107.46 \\
\hline & & & & & & 150 & 109.29 \\
\hline \multirow[t]{3}{*}{ MDC } & ND & 96,789 & 51,465 & 100,144 & 149,711 & 50 & 106.34 \\
\hline & & & & & & 100 & 103.47 \\
\hline & & & & & & 150 & 103.12 \\
\hline \multirow[t]{3}{*}{ Benzene } & ND & 2695 & 1451 & 2750 & 4161 & 50 & 107.68 \\
\hline & & & & & & 100 & 102.04 \\
\hline & & & & & & 150 & 102.93 \\
\hline \multirow{2}{*}{ Toluene } & & & & & & 100 & 103.86 \\
\hline & & & & & & 150 & 105.47 \\
\hline
\end{tabular}

IPA: Isopropyl alcohol, MDC: Methylene dichloride, LOQ: Limit of quantitation

Table 9: Recovery data at LOQ level

\begin{tabular}{|c|c|c|c|c|c|c|}
\hline No. of injections & Area of methanol & Area of acetone & Area of IPA & Area of MDC & Area of benzene & Area of toluene \\
\hline Run-1 & 31,574 & 29,689 & 5283 & 2670 & 157 & 14,391 \\
\hline Run-2 & 31,742 & 27,624 & 5277 & 2775 & 164 & 14,530 \\
\hline Run-3 & 31,674 & 29,144 & 5600 & 2727 & 152 & 14,879 \\
\hline Average area & 31,663 & 28,819 & 5387 & 2724 & 158 & 14,600 \\
\hline STD avg. area $(n=6)$ & 10,382 & 21,902 & 4738 & 2583 & 153 & 13,027 \\
\hline In sample avg. area $(n=3)$ & 20,720 & 6248 & ND & ND & ND & ND \\
\hline$\%$ recovery & 105.41 & 103.05 & 113.69 & 105.46 & 103.05 & 112.07 \\
\hline
\end{tabular}

IPA: Isopropyl alcohol, MDC: Methylene dichloride, LOQ: Limit of quantitation

Table 10: Ruggedness data for six organic volatile impurities

\begin{tabular}{|c|c|c|c|c|c|c|c|}
\hline \multicolumn{2}{|c|}{ Different days and analysts } & \multirow{2}{*}{$\begin{array}{l}\begin{array}{l}\text { \%RSD for } \\
\text { methanol }\end{array} \\
3.91\end{array}$} & \multirow{2}{*}{$\begin{array}{l}\text { \%RSD for } \\
\text { acetone }\end{array}$} & \multirow{2}{*}{$\begin{array}{l}\begin{array}{c}\% \mathrm{RSD} \\
\text { for IPA }\end{array} \\
3.00\end{array}$} & \multirow{2}{*}{$\begin{array}{l}\text { \%RSD for } \\
\text { MDC } \\
4.37\end{array}$} & \multirow{2}{*}{$\begin{array}{l}\begin{array}{l}\% \text { RSD for } \\
\text { benzene }\end{array} \\
4.03\end{array}$} & \multirow{2}{*}{$\begin{array}{l}\begin{array}{l}\text { \%RSD for } \\
\text { toluene }\end{array} \\
3.29\end{array}$} \\
\hline Day-1 & Analyst-1 & & & & & & \\
\hline & Analyst-2 & 7.69 & 4.53 & 3.30 & 5.27 & 4.4 & 2.56 \\
\hline & Analyst- 1 and 2 & 5.81 & 3.64 & 7.41 & 4.83 & 4.21 & 2.81 \\
\hline \multirow[t]{3}{*}{ Day-2 } & Analyst-1 & 7.05 & 2.09 & 3.76 & 8.27 & 5.86 & 2.34 \\
\hline & Analyst-2 & 8.54 & 3.39 & 5.06 & 3.09 & 5.56 & 1.53 \\
\hline & Analyst- 1 and 2 & 7.48 & 2.88 & 4.52 & 6.77 & 5.03 & 1.93 \\
\hline Analyst-2 & Day- 1 and 2 & 8.48 & 3.91 & 4.08 & 4.92 & 4.92 & 3.21 \\
\hline
\end{tabular}

IPA: Isopropyl alcohol, MDC: Methylene dichloride 
Table 11: Robustness data for six organic volatile impurities

\begin{tabular}{|c|c|c|c|c|}
\hline \multirow[t]{2}{*}{ Name of OVI's } & \multicolumn{2}{|l|}{ Flow rate $(\mathrm{mL} / \mathrm{min})$} & \multicolumn{2}{|c|}{ Vial condition temperature $\left({ }^{\circ} \mathrm{C}\right)$} \\
\hline & $2.5 \mathrm{~mL} / \min (\mathrm{RSD} \%)$ & $3.1 \mathrm{~mL} / \min (\mathrm{RSD} \%)$ & $75^{\circ} \mathrm{C}$ (RSD \%) & $85^{\circ} \mathrm{C}(\mathrm{RSD} \%)$ \\
\hline Methanol & 9.47 & 5.02 & 3.84 & 4.83 \\
\hline Acetone & 3.60 & 1.62 & 3.19 & 6.23 \\
\hline IPA & 9.66 & 6.61 & 6.27 & 2.86 \\
\hline MDC & 5.01 & 4.72 & 2.15 & 3.48 \\
\hline Benzene & 5.16 & 3.05 & 3.76 & 2.57 \\
\hline Toluene & 2.53 & 3.04 & 3.23 & 3.50 \\
\hline
\end{tabular}

IPA: Isopropyl alcohol, MDC: Methylene dichloride

Table 12: Six organic volatile impurities content in tablet analysis

\begin{tabular}{|c|c|c|c|c|c|c|c|}
\hline Name of drug & Label claim (mg) & Methanol (ppm) & Acetone (ppm) & IPA (ppm) & MDC (ppm) & Benzene (ppm) & Toluene (ppm) \\
\hline $\begin{array}{l}\text { Sumatriptan } \\
\text { succinate }\end{array}$ & 100 & Not detected & Not detected & Not detected & Not detected & Not detected & Not detected \\
\hline
\end{tabular}

IPA: Isopropyl alcohol, MDC: Methylene dichloride

Table 13: Solution stability data for six OVI's and sumatriptan succinate API

\begin{tabular}{|c|c|c|c|c|}
\hline Methanol (h) & Area in standard & $\%$ solution stability for standard & Area in sample & \% solution stability for API sample \\
\hline At 0 & 429,510 & Not applicable & 23,615 & Not applicable \\
\hline At 12 & 418,456 & 97.43 & 23,516 & 99.58 \\
\hline At 24 & 409,560 & 95.36 & 23,356 & 99.32 \\
\hline Acetone (h) & Area in standard & $\%$ solution stability for standard & Area in sample & $\%$ solution stability for API sample \\
\hline At 0 & 852456 & Not applicable & 7325 & Not applicable \\
\hline At 12 & 839521 & 98.48 & 7295 & 99.59 \\
\hline At 24 & 824562 & 96.73 & 7245 & 99.31 \\
\hline At 0 & 1658845 & Not applicable & Not detected & Not applicable \\
\hline At 12 & 1611450 & 97.14 & Not detected & Not applicable \\
\hline At 24 & 1601256 & 96.53 & Not detected & Not applicable \\
\hline MDC (h) & Area in standard & $\%$ solution stability for standard & Area in sample & $\%$ solution stability for API sample \\
\hline At 0 & 94215 & Not applicable & Not detected & Not applicable \\
\hline At 12 & 92256 & 97.92 & Not detected & Not applicable \\
\hline At 24 & 90145 & 95.68 & Not detected & Not applicable \\
\hline Benzene (h) & Area in standard & $\%$ solution stability for standard & Area in sample & $\%$ solution stability for API sample \\
\hline At 12 & 2515 & 95.09 & Not detected & Not applicable \\
\hline At 24 & 2499 & 94.48 & Not detected & Not applicable \\
\hline Toluene (h) & Area in standard & $\%$ solution stability for standard & Area in sample & $\%$ solution stability for API sample \\
\hline At 0 & 521325 & Not applicable & Not detected & Not applicable \\
\hline At 12 & 509523 & 97.74 & Not detected & Not applicable \\
\hline At 24 & 501236 & 96.15 & Not detected & Not applicable \\
\hline
\end{tabular}

IPA: Isopropyl alcohol, MDC: Methylene dichloride, OVI's: Organic volatile impurities, API: Active pharmaceutical ingredients

\section{Sumatriptan succinate tablet analysis}

The prepared sumatriptan succinate tablet solution $(250 \mathrm{mg} / \mathrm{mL})$ was injected. The six organic volatile impurities content in sumatriptan succinate tablets was found within the specifications. The results and typical chromatograms were shown in Table 12 and Fig. 9.

\section{Solution stability}

Stability of six organic volatile impurities standard and sumatriptan succinate API sample prepared in DMSO as a diluent. Three-time intervals solutions (initial, after $12 \mathrm{~h}$, and after $24 \mathrm{~h}$ ) were prepared on the same day and keep them at room temperature. Initial, after $12 \mathrm{~h}$, and after $24 \mathrm{~h}$ OVI's standard and sumatriptan succinate API solutions were injected at that time point. Then, the calculated the $\%$ of solution stability for the area of initial, after $12 \mathrm{~h}$, and after $24 \mathrm{~h}$ injections. The $\%$ of solution stability is $100 \pm 10 \%$. From these stability results, we can found that six organic volatile impurities standards and sumatriptan succinate API were stable up to $24 \mathrm{~h}$. The corresponding data are presented in Table 13.

\section{CONCLUSION}

The six OVI's, methanol, acetone, IPA, dichloromethane, benzene, and toluene, were well separated from each other and quantified by the proposed method. This method was also applied for the quantification of organic volatile impurities in the marketed sumatriptan succinate, which were present in ppm specification limits as per ICH guidelines. The proposed method was validated as per the ICH guidelines and the results revealed that the method was scientifically. This investigation may be helpful to the manufacturers for controlling and minimization of the organic volatile impurities. Moreover, this method was found to be applicable for the routine analysis of the sumatriptan succinate in the pharmaceutical industry.

\section{AUTHORS' CONTRIBUTIONS}

Dr. K. Prasada Rao supervised the manuscript preparation and reviewed the manuscript. I would like to thank the whole staff of the Chemistry Department of Bapatla Engineering College for their technical support and productive discussions. 


\section{AUTHORS' FUNDING}

I would like to thank to Chemistry department of Bapatla Engineering College for their Financial support.

\section{CONFLICTS OF INTEREST}

The authors declare that they have no conflicts of interest.

\section{REFERENCES}

1. Sagar DS, Paresh UP, Bhanubhai NS. Development and validation of reversed-phase high performance liquid chromatographic method for estimation of sumatriptan succinate in pharmaceutical dosage form. Int J Drug Dev Res 2011;3 Suppl 4:266-9.

2. First-Time Generic Approvals: Seasonale, Imodium Advanced, and Topamax. Available from: https://www.Medscape.com. [Last accessed on 2006 Sep 22; Last accessed on 2013 Jul 11].

3. Singh A, Singh SB. Simultaneous estimation of sumatriptan succinate, metoclopramide hydrochloride and paracetamol by RP-HPLC method. J Pharm Sci Res 2012;4 Suppl 6:1848-51.

4. International Council for Harmonisation. International Conference on Harmonisation of Technical Requirements for Registration of Pharmaceuticals for Human Use. ICH Harmonized Tripartite Guidelines Q3C Impurities: Residual Solvents. Switzerland: International Council for Harmonisation; 1997. 